\title{
Pedagogical design in the design of educational materials when creating electronic courses
}

\author{
O.A. Kalimullina ${ }^{1 *}, A . N$. Afzalova $^{2}$, and Y.N. Kuznetsova ${ }^{3}$ \\ ${ }^{1}$ Volga Region University of Sports and Tourism, Kazan, Russia \\ ${ }^{2}$ Volga Region University of Sports and Tourism, Kazan, Russia \\ ${ }^{3}$ Volga Region University of Sports and Tourism, Kazan, Russia
}

\begin{abstract}
The article indicates the importance of the principles of pedagogical design and pedagogical design in ensuring the effectiveness of e-learning. The author considers the features and advantages of blended learning for both students and university teachers in general, shows the possibilities of using the electronic environment within the framework of full-time and distance learning. The practical aspect of these problems is considered, which is associated with the fact that few teachers are ready to master the latest technologies, design the content and organizational aspects of the digital educational space, adapt the educational process to the requirements of an innovative society, since there are no ideas about the digital educational space as a whole.
\end{abstract}

\section{A problem statement}

The report on Digital policy prepared by the European Commission, implemented in Europe and beyond, which analyzed more than 40 international educational projects in the field of digital education, underlines the importance of the current international policy and the need for further work on the development of the digital educational space.

According to this report, the introduction of information technologies in the educational process leads to the improvement of the student's learning outcomes. The analysis of 77 educational projects conducted by McEwan in 2015 showed that the introduction of information and communication technologies in the educational process had the greatest positive effect, the indicator of the effectiveness of students ' work was equal to $0.15 \mathrm{SD}$, while the indicator of the effectiveness of training in small groups was $0.12 \mathrm{SD}$. Kremer's analysis of 32 control tests determined that the use of digital technologies in most cases increased the effectiveness of the organization of the educational process. Reviews of the latest technologies also show that these tools have a positive impact on students ' achievement of better learning outcomes. For example, a study conducted by Hassler and his colleagues in 2015 showed that out of 23 programs implemented through the use of

\footnotetext{
*Corresponding author: prof-ped.gpa@mail.ru
} 
tablets, 16 made significant progress in mastering knowledge. Tamim and his colleagues conducted a study in 2015 that only confirmed the above results of the introduction of information and communication technologies in the educational process. The authors summarized the results of 27 assessments of the effectiveness of tablet use in the learning process and found that studies comparing the contexts of tablet use with those without their use indicate a significant average effect size of 0.23 SD. Thus, the above analysis of statistical data proves the need for the development of digital educational space on the territory of the Russian Federation [8-20].

From 08.04. to 10.04.2020, the Department of Education Quality Management, with the participation of the deans of the faculties, conducted a sociological survey, the purpose of which was to find out the satisfaction of students of the Volga GUFKSIT (hereinafter referred to as the Academy) with the conditions for implementing the educational process using e-learning and distance learning technologies during the application of measures to combat coronovirus infection (COVID - 19). This goal was achieved by solving a number of tasks that allowed us to identify:

1. Opinion of bachelors, undergraduates, and postgraduates (hereinafter referred to as students) on the conditions of training in the distance learning format;

2. Students ' opinion on the readiness of teachers to fully switch to the distance learning format;

3. Students ' opinion on the conditions for organizing classes in a remote format;

4. Students ' opinion on the sufficiency of contacts with teachers within the educational process using e-learning and distance learning technologies;

5. Students ' opinion on the difficulties of remote interaction with teachers and the organization of the educational process: technical and methodological;

6. The extent to which students use the Academy's library resources during distance learning;

7. Methods of organizing classes by teachers;

8. Students ' opinion about the functionality of the Moodle system;

9. Students ' wishes for improving the educational process using e-learning and distance learning technologies;

10. Students ' opinion about their desire to continue their educational activities at the Academy in the future using e-learning and distance learning technologies.

The object of the study is students of the bachelor's, master's, and postgraduate levels of full-time education. The planned sample size was 2,694 people, the actual sample size was 1,386 people (51.4\%). Research method: a survey of students by filling out a questionnaire in Google (appendix "Questionnaire of students' satisfaction with the conditions for implementing the educational process using electronic learning and distance learning technologies").

We are interested in the third set of questions, which was devoted to identifying the main difficulties that students face when implementing the educational process using elearning and distance learning technologies during the coronovirus (COVID-19). To the first question of this block, "Does the distance learning format cause you any difficulties?» only $35.64 \%$ of the students answered that they did not encounter any difficulties (Figure 1). 


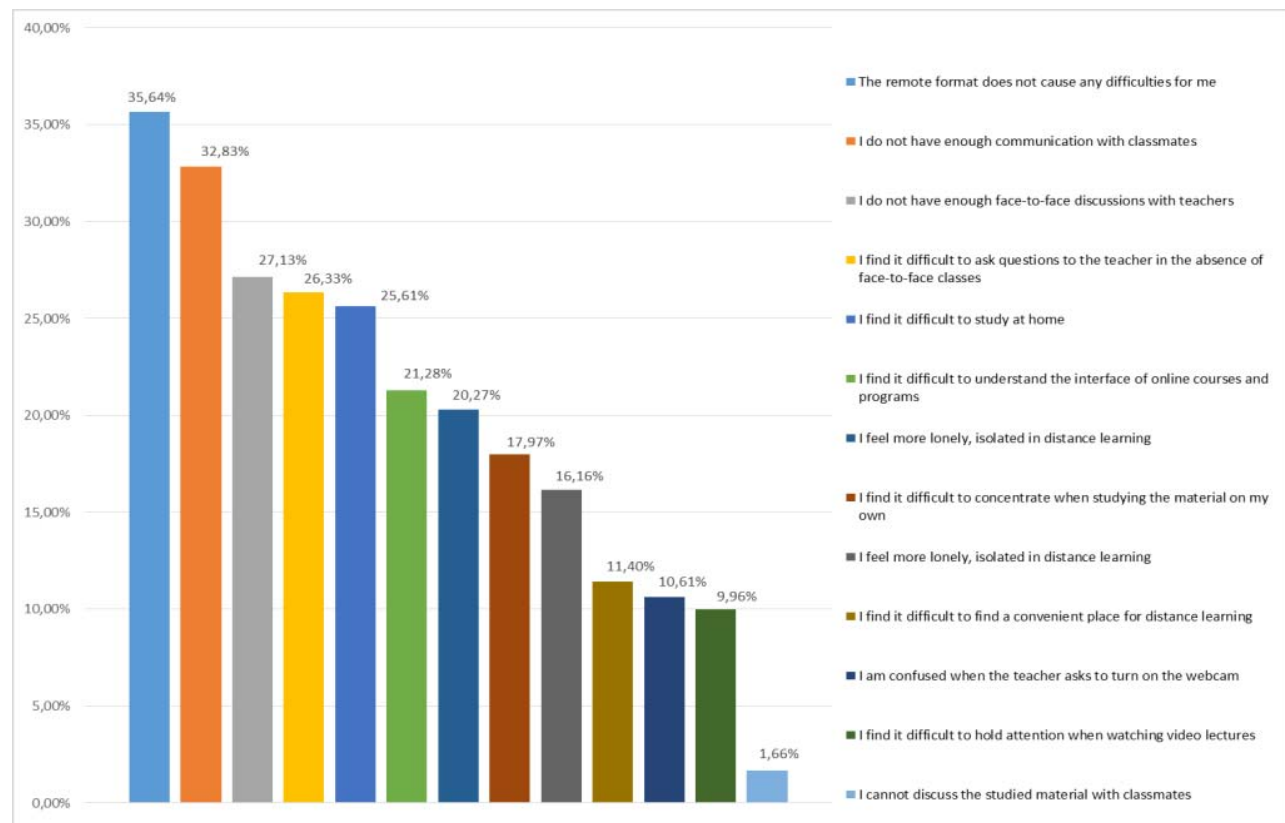

Fig. 1. Difficulties faced by students in the framework of distance learning (multiple choice of answers).

In addition, a number of students in an open form added to the list of difficulties that they have to face during distance learning: - "Very heavy load in some subjects" - $0.22 \%$; " Yes, too much time has to be spent at the computer. Eyesight and health deteriorate, too long to sit at the computer" - $0.14 \%$;- "They ask a lot of homework, without analyzing the theoretical material on these topics" - $0.07 \%$;- "It is extremely inconvenient to take photos of the tasks done, and then load them into the computer, besides it takes a lot of time" $0.07 \%$; - "There is a lot of homework and little explanation on various topics. It is difficult to perform tasks in computer science when the teacher can not explain this or that task" 0.07\%; - "Some teachers do not give feedback on completed tasks" - $0.07 \%$.

Students who took part in the survey were asked to express their wishes in an open form about providing them with assistance in working in a remote format. The following requests were received:- " The teacher's explanation of homework, that is, how to do them, you need specifics. Personally, I do as I understand it, then the teachers say that it should have been done differently and have to redo it»; - "I would like to get more lecture material and more explanations from the teacher»; - "Help with the use of resources, in explaining the topics studied»; - "All the time-discussion with classmates, where to go and what to do. You get tired of it, you waste your time»; - "There are many things that, when I don't understand, I would like to ask, but because of the distance, I can't or don't dare to ask, and it's hard for me to do one thing for a long time, if there is no one near me to help me"; - " Sometimes I can't go to the DO, sometimes in the online chat, questions do not come, like the guys, or come late»; - "Sometimes you don't understand the essence of homework, where to go or what to do»; - "The answer forms are constructed crookedly, the tasks are set crookedly»; - "Personal explanation or presentation of the material of some subjects"; "Many tasks given by teachers are not clear, so additional information is needed from the teachers themselves";- " Not everything is opened from the phone /tablet, not all lectures and practices in one program. Some do not have the ability to $\log$ in from a PC / laptop»; "Setting up communication with teachers and explaining the material they give, it is very difficult to understand everything yourself";- "Not all tasks are clear and there are a lot of 
them"; - "Not all courses can be found in the "Courses" section, you need to distribute the courses. If the course has already passed, then transfer it to the transferred ones, otherwise you have to search for a long time. Also, some courses are sometimes not found at all, you need to go to the "Course" for a very long time through the choice of forms"" - " Not all teachers get in touch in a timely manner, we go to the DO and do not even know what to do»; - "I can't find the item that the pair is walking on»; - "It is not possible to focus on the lesson, and therefore the assimilation of information has fallen by $65-70 \% "$; - " There is not enough advice from teachers and more precise wording of tasks»; - "Some subjects are so incomprehensible that it is impossible to explain them using the remote system»; "Some teachers don't explain how to do their homework. Do not throw off the plan for which you need to perform it and what sub-items should be present»; - "Feedback, help in mastering the material»; - "Explain how the interface works»); - "Explain how to work in the DO. We weren't trained to do that. We weren't ready for this»; - "Teacher feedback, explanation of the material»; - "Getting more information about how and in what subjects attendance is evaluated. What is the chat for in the DO. What is Mooldy and much more"; - " Getting assignments not in the DO, but through the headman; not in turn, but immediately for the semester in each subject»; - "You just need to make sure that the load from teachers is given less and evenly"; - " Make it easier to navigate through topics. I want everything to be on the shelves. Sometimes I get confused and get lost, I did not understand the site properly for a year of training, only by $60 \%$. In the very first days of my studies, I didn't understand anything. I didn't know where to click»; "I don't understand some of the material." The greatest number of questions and suggestions are related to the teacher's explanation of tasks and the complexity of orientation in the Moodle system interface.

The last question analyzed the students ' desire to continue their studies at the Academy in the future using e-learning and distance learning technologies. The data is shown in Figure 2.

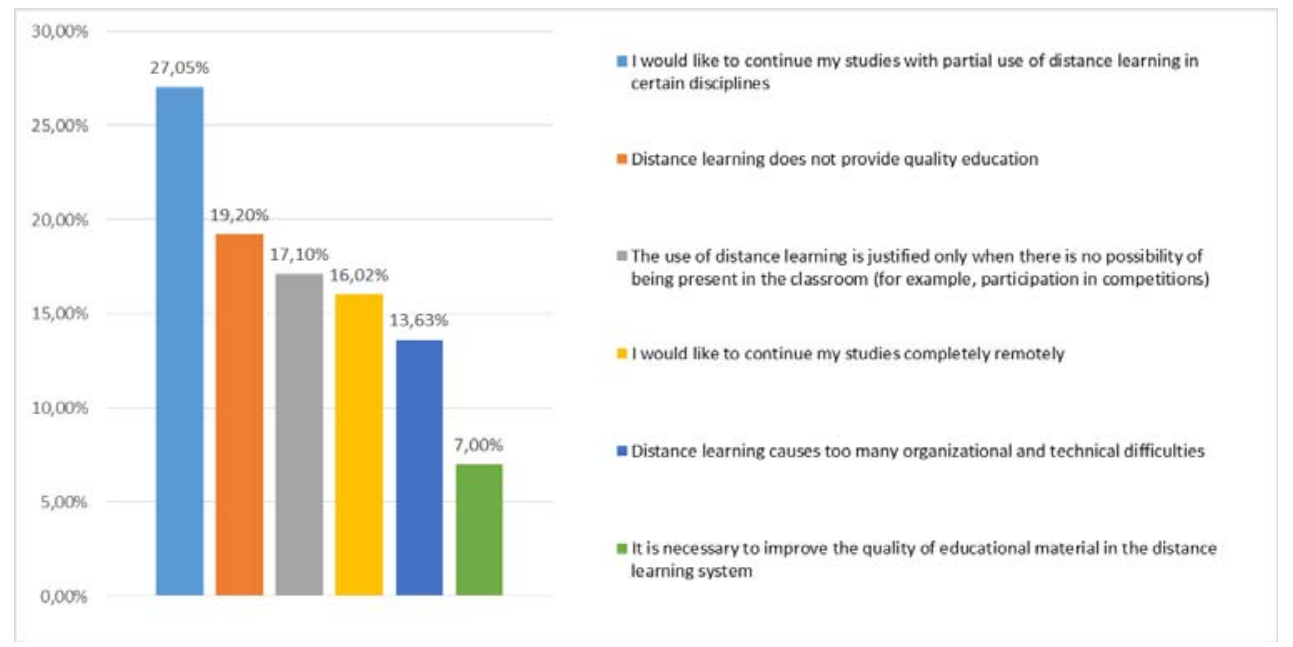

Fig. 2. Indicators of students ' desire to continue their studies at the Academy in the future using elearning and distance learning technologies.

As we can see from Figure 2, only $27.05 \%$ of students would like to continue their full distance learning in the future. Students were dissatisfied with the quality of distance learning courses.

The purpose of educational design is to determine the most acceptable and digestible way to present educational content. It's the science of creating an effective and engaging learning experience - the science of how people learn. 
Consequently, the ability to assess the attitudes of the target audience, knowledge gaps, and learning goals is a key factor in pedagogical design. To achieve these goals, teachers have to become designers of training programs that include an extensive repertoire of roles and responsibilities and are far from limited to them:

* Define clear and actionable learning objectives and create compelling content that matches them.

* Conceptualization of educational graphics, multimedia, user interface, and final product.

* Analysis and application of principles, trends and best practices related to educational design and learning technologies.

* Develop exercises, assignments, and assessments to maximize students ' learning potential.

* Development of supporting materials and resources that include multimedia in various formats (for example, audio, video, screencasts, gamification, scripts, role-playing games).

* Development of various assessment methods, including quizzes, tests and surveys, to assess the effectiveness of the course.

The transition of universities to distance learning dictates its own rules for teachers. Teachers have to become designers of their courses and translate these courses online. The world of educational design is closely related to the psychology of learning behavior. The teacher should use the psychology that underlies how students remember and assimilate information. When creating a distance learning course, teachers often ask themselves these questions: What is the best way to present a block of text - as an interactive graphic, presentation, or video file? How best to divide the course into micro-learning modules for faster and easier learning?

\subsection{The objective of the work}

To answer these questions, we'll look at the ADDIE instructional design model. You can think of models and theories of learning design as applied psychology - that is, they make the abstract and theoretical principles of behavioral psychology concrete by applying them in practice. There are many models, theories, and strategies for instructional design, but essentially all of them use the ADDIE model, an acronym that stands for analysis, design, development, implementation, and evaluation. The ADDIE model is a teaching design methodology that helps from the very beginning to the very end of the curriculum design process.

The table1 below shows in detail what each element of the ADDIE model entails.

Table 1. ADDIE model.

\begin{tabular}{|l|l|}
\hline Analysis & $\begin{array}{l}\text { The analysis phase should determine what the purpose of the course is, } \\
\text { as well as collect information about the learning environment and } \\
\text { demographic data of the target audience, such as age, gender, primary } \\
\text { language, formal education, profession, and culture. }\end{array}$ \\
\hline Design & $\begin{array}{l}\text { The next step involves developing the overall course structure. You need } \\
\text { to write specific, actionable learning goals, developing a general plan } \\
\text { and teaching methods for the course. This stage may include a } \\
\text { storyboard for the course. }\end{array}$ \\
\hline Development & Once a course has been developed or planned, it is only a matter of \\
\hline
\end{tabular}




\begin{tabular}{|c|l|}
\hline Implementation & $\begin{array}{l}\text { producing or developing the materials. You start writing content, } \\
\text { searching for graphics and multimedia, creating videos, and creating } \\
\text { scores with an industry-standard e-learning tool like, for example, } \\
\text { Moodle }\end{array}$ \\
\hline Evaluation & $\begin{array}{l}\text { Then you simply deliver or embed the course directly into the Learning } \\
\text { Management System (LMS). }\end{array}$ \\
\hline $\begin{array}{l}\text { When the course is completed by the students, you will need to evaluate } \\
\text { its een achieness. Here you need to find out if the learning goals have }\end{array}$ \\
\hline
\end{tabular}

\section{Results of the research}

Effective online learning does not happen by chance, it is the end result of a systematic, systematic development process. To create an e-learning course, it is not enough to be an expert in a particular topic, it is necessary to take into account the principles of educational design.

In this article, we will take as a basis the nine principles of Robert Gagnier's teaching and show how to apply them in the course development process.

Robert Gagnier was an American educational psychologist who made a major contribution to the development of the science of education in the mid-twentieth century. He found that there are some patterns in how people process information, and proposed a nine-step structure that describes in detail all the elements necessary for effective learning. Gagne's nine teaching principles can serve as a checklist to help teachers structure their learning.

Each step in the model corresponds to a form of communication or activity that helps the learning process. These include preparation, training and practice, evaluation and transfer.

Preparation:

Attract attention

- Inform students about the goals

- Encourage recall of previous knowledge

Training and practice

- Submit new content

- Providing recommendations

- Identify performance

- $\quad$ Provide feedback

Evaluation and transfer

- Evaluate the effectiveness of training

- Consolidate the acquired knowledge.

When each step is performed in turn, the learner is much more likely to have an easier time memorizing the information or consolidating the acquired skill.

Using the nine principles of Gagnier, the teacher will be able to build their course so that students will learn this course best remotely, mostly by studying independently. This approach works well not only in blended learning, but it can also be applied to e-learning.

Let's see how we can apply this framework to build an online course.

Principle 1: Attract Attention (Reception) 
A strong start is your opportunity to engage the learner and prepare the ground for learning. Start your course with an introduction or an action that will cause the learner to distract from other tasks and focus their attention on the content of your training.

Consider the most common ways to attract attention at the beginning of the course, for example:

* share an unexpected fact or statistic;

* ask thought-provoking questions;

* suggest activities that involve students in the learning process.

Adding multimedia elements can add value to your content and engage your listeners on both an auditory and visual level.

Principle 2: Informing students about the goals (extracting information)

Setting learning goals in advance demonstrates the added value that your course brings and helps the student set expectations about what lies ahead.

To familiarize students with the goals of the online course, you can list them on the slide. For each goal, it is useful to describe the required performance, give the expected performance standard, and indicate what the successful outcome will be.

Align each goal with the results based on the knowledge or skills that your students will achieve.

Principle 3: Stimulate memories of previous learning (waiting)

Link your content to the existing knowledge or skills of your students that they acquired in the previous stage of mastering the kura material. This will help them approach the new material with a sense of confidence. To strengthen students ' knowledge, you can add a short summary of the knowledge or concepts they have already mastered, or (even better) check how well they have memorized the course material using a test.

Principle 4: Present New Content (Selective Perception)

This is where you provide new knowledge, information, and skills to your students. Don't rely on text alone to convey information; include appropriate images, graphs, tables, and graphs in your course to help the student visualize and understand each concept. Consistently deliver your content in a way that allows students to absorb new information without feeling overwhelmed.

If you already have PowerPoint presentations, you can use Moodle to turn them into full-price e-courses in a few clicks. Or you can add all the necessary content to the slides to build an interactive course from scratch

You can also share your knowledge with a tutorial video.

Principle 5: Provide training guidance (semantic coding)

Support your students by providing helpful tips on how to learn a new skill. Provide examples or coaching tips on learning content and guide students through the useful resources available to them.

You can suggest that you study the proposed course more effectively by including case studies, infographics, workbooks, concept maps, or other learning objects.

Principle 6: Getting Performance (Responsiveness)

At this stage of the process, your student should be able to demonstrate the knowledge or skills they have gained from your course. Include interactive elements that require the student to use the acquired knowledge.

With Moodle, you can create a dialog box. This type of interaction challenges students to demonstrate their ability to remember and apply knowledge in a realistic work scenario. You can vary the result depending on how the student answers each question.

Principle 7: Provide Feedback (Reinforcement)

Provide immediate feedback after the student demonstrates their knowledge or skills. Positive feedback will strengthen what the student is doing well. Gentle and constructive advice will help the student identify and overcome mistakes in knowledge or skills. 
Add an appropriate comment to each response option in the dialog box. You can create informational scenes to pinpoint where the student made a mistake and explain what the right move would be at that point, or to praise the student for making the right choice.

Principle 8: Evaluating The Effectiveness Of Training (Extracting Information)

At the end of the course, evaluate your students with tests and quizzes.

Principle 9: Improving the efficiency of knowledge storage and transfer (reinforcement)

Provide your students with additional resources that will add to the knowledge of the new course. You can create instructions, catalogs, and other reference materials that your students will always have at hand and can view to update their knowledge at any time.

\section{Conclusions}

The considered principles were successfully implemented in the creation of an online educational course dedicated to the "Introduction of ICT technologies in the educational process" due to the idea of implementing the federal projects "Digital Educational Environment", "Teacher of the Future", which are part of the national project "Education", in particular, the need to address such issues as "development of a methodology for the introduction of ICT technologies in educational programs, the creation of an integration platform for continuing education, improving the level of competence of teachers in the field of communication and information technologies", as well as the situation that arose in connection with the spread of the COVID-19 virus infection, which forced us to restructure the educational process in the shortest possible time and think about further reforming the digital educational space.

The online educational course "Introduction of ICT technologies in the educational process" is designed to study the mechanisms of working with innovative information and communication technologies in the context of a specific lesson.

It was decided to create an online educational course "Introduction of ICT technologies in the educational process" on the Udemy platform. This platform has a number of advantages. First, if a user creates a free online course, there is no charge for its creation, in contrast to the platforms Moodle, Teachable, LearnDash, WordPress Plug-Ins, which provide a monthly payment regardless of the type of course. Secondly, unlike the Google Classroom platform, the user is provided with a larger list of tools that can be implemented in an online educational course and does not need to have a mandatory Google account. Russian Russian language support is the most important advantage, and the platform has a Russian interface.

\section{References}

1. V.I. Blinov., I.S. Sergeev., E.Yu Yesenina, The main ideas of the didactic concept of digital professional education and training, 24 (2019)

2. M.V. Gruzdev, I.Yu. Tarkhanova, Formation of the "new didactics" of teacher education in the context of global renewal and digitalization, Yaroslavl Pedagogical Bulletin, 3, 48-49 (2019)

3. M.A. Choshanov The evolution of the view of didactics: is it time for a new didactics?, Didactics of a professional school, 26-27 (2013)

4. L.A. Pozharskaya, O.A. Rastorgueva, Distance education: deficits and prospects, Council of Rectors, 10, 69-75 (2013) 
5. I.V. Polozhentseva, Genesis, evolution and prospects for the development of distance education, The world of science, 1(5), 1-10 (2017)

6. E.V. Polyakova, Innovatsionnoe obshchestvo: sinergeticheskiy podkhod, Innovative society: a synergetic approach, 41 (2010)

7. V.S. Stepin, A turning point in civilizational development. Points of growth of new values, Convergent technologies (NBICS) and transhumanistic evolution, 272 (2013)

8. Tolstykh A.A., Kuznetsova E.D., Poddubny S.S., Types and features of the use of educational blogs, 6, 23-28 (2017)

9. M. Kremer, E. Miguel, R. Thornton, Incentives to learn, Review of Economics and Statistics, 91(3), 437-456 (2009)

10. B. Hassler, L. Major, S. Hennessy, Tablet use in schools: A critical review of the evidence for learning outcomes, Journal of Computer Assisted Learning, DOI: 10.1111/jcal.12123 (2015)

11. R. Tamim, M.E. Borokhovski, D. Pickup, R. Bernard, Large-Scale, GovernmentSupported Educational Tablet Initiatives. Burnaby, Common Wealth of Learning (2015)

12. S. Michael, Z. Susan, S. Sharon, Teaching and Learning at a Distance, Foundations of Distance Education 7th., 39-40 (2019)

13. P. Ochieng, Children Rights to Education using ADDIE Model Approach in Arid and Semi Arid Lands (ASAL), African Journal of Education, Science and Technology, 5(4), 290-297 (2020)

14. A. Schleicher, Schools for 21st-Century Learners: Strong Leaders, Confident Teachers, Innovative Approaches, International Summit on the Teaching Profession (2015)

15. S. Srivastava, The Spirit of Public Libraries in Free Culture (2005)

16. A. Smith, M. Anderson, Social Media Use in 2018, 14 (2020)

17. T. Standage, Writing on the wall: Social media, 210 (2013)

18. Statista Most popular social networks worldwide as of January 2020, ranked by number of active users (2020)

19. P. Suppes, M. Jerman, G. Groen, Arithmetic drills and review on a computer-based teletype, The Arithmetic Teacher, 13(4), 303-309 (1966)

20. R. Tamim, E. Borokhovski, D. Pickup, R. Bernard, Large-Scale, GovernmentSupported Educational Tablet Initiatives, 215 (2015) 